\title{
REMOTE SENSING DETECTION AND IMPACT ANALYSIS OF TIBETAN HUMAN LANDSCAPE IN JIUZHAIGOU
}

\author{
Jun Ma ${ }^{1, *}$, Deren $\mathrm{Li}^{1}$, Md Enamul Huq ${ }^{1}$, Qimin Cheng ${ }^{2}$ \\ ${ }^{1}$ State Key Laboratory of Information Engineering in Surveying, Mapping and Remote Sensing, Wuhan University, No. 129 Luoyu \\ Road, Wuhan, Hubei, China - makuna@gmail.com (J.Ma),drli@whu.edu.cn (D. Li), enamul huq@whu.edu.cn (M.E.Huq) \\ ${ }^{2}$ School of Electronics Information and Communications, Huazhong University of Science and Technology, 1037 Luoyu Road, \\ Wuhan 430074, China - chengqm@hust.edu.cn (Q.M.Cheng)
}

KEY WORDS: Change detection, Remote sensing, Vulnerability evaluation model, Human landscape

\begin{abstract}
:
The qualitative analysis of human landscape vulnerability is widely recognized, but quantitative analysis needs a lot of manpower, material resources as well as time to carry out the social observation. Based on remote sensing and spatial data, quantitative analysis of human landscape vulnerability will change this situation. This paper put forward a vulnerability evaluation model for change detection with remote sensing time series images and spatial tourism data. It is not only a quickly analysis tool which spans from the earth observation to the social observation for quantitative evaluation, but also an assistant tool for decision-making from change detection analysis to trend analysis.

The vulnerability evaluation model of Jiuzhaigou Tibetan human landscape highlights the vulnerability of the whole region has increased significantly. The good structure ratios of bio-abundance are the basis of the human landscape protection, but the activities of ice and snow areas may be a natural factor for the migration of native along the tour roads in the valley from hillsides. The impact of tourism activities is far less than the natural environment. But tourism activities have inevitably affected the human landscape protection, and its negative index benefit is almost three times as much as the positive index benefit of protection measures. Especially, with the change of production and lifestyle of native brought by tourism activities, the human landscape is gradually disappearing. Further development of tourism activities will also extend the impact to the Balance Zone. It is urgent to reconstruct the current management model of human landscape.
\end{abstract}

\section{INTRODUCTION}

Landscape, in geography refers to the synthesis of various geographical phenomena on the earth's surface (Philip, 1885). It is classified as natural landscape and human landscape. However, the human landscape is the result of human culture acting on natural landscape (Sauer, 1925). Compared with the previous simple level of heritage, human landscape emphasizes the interaction, interdependence and sustainable development of human and nature, which is more in line with the current concept of sustainable development of heritage tourism (Farina, 2000).

The core of human landscape is human-land relationship (Li, et al., 2014). The material human landscape includes the elements of behaviour, architecture, space, structure and environment. The studies of human landscape based on remote sensing mainly focuses on land use change detection and analysis. For example, Angelstam used Landsat data to evaluate the authenticity of European countryside, and discussed the Human value of settlement protection with the evolution of landscape pattern of European villages (Anglestam, et al., 2003). Similarly, Martnez applied remote sensing quantitative methods to construct a biodiversity loss assessment model for European human landscape (Martínez, et al., 2010). Chu used Landsat TM data and showed the land use change brought by tourism in Zhouzhuang, an ancient town of China (Chu, 2013). More recently, Maimaiti used remote sensing technology to analyse the spatial pattern of historical and human landscape in Turpan region (Maimaiti, 2018). In this study, a landscape pattern analysis of landscape ecology was done, based on the national standards such as "Classification of Land Use Status" (GB/T 21010-2017) (Resources, 2017), "Technical Specification for Assessment of Eco-environmental Status" (HJ192-2015) (Protection, 2015), and field survey. The vulnerability evaluation system was designed by Analytic Hierarchy Process (AHP) (T.L, 2001). The vulnerability evaluation model was constructed by Non-dimensional Range Normalization and Weight Method of Factor Standard Deviation. Finally, the change detection and analysis were carried out in the study area as an example.

\section{STUDY AERA AND DATA}

Jiuzhaigou Park is located in Jiuzhaigou county, Sichuan province of China, with a study area of $657.0036 \mathrm{~km} 2$ and an average elevation of $3609 \mathrm{~m}$. It is situated between longitudes $103^{\circ} 46^{\prime} \sim 104^{\circ} 4^{\prime} \mathrm{E}$ and latitudes $32^{\circ} 51^{\prime} \sim 33^{\circ} 19^{\prime} \mathrm{N}$. The Valley is formed with nine Tibetan villages, including Heye, Shuzheng, Zechawa, Panya, Yala, Jianpan, Heijiao, Rexi and Guodu. By the end of 2016, there were 1340 native people and 356 households. The vertical structure of the material Human landscape is manifested by the forms of Longda, Prayer Flag, Hada, Lingta, Mill, Tibetan Village and Bonpo Temple. Jiuzhaigou was listed in the World Natural Heritage and World Biosphere in 1992 and 1997 respectively (Liu, et al., 2007).

This paper selected Jiuzhaigou Tibetan villages, Bonpo Temple and Tibetan settlement as the research objects of material Human landscape. Because, in the alpine valley of Jiuzhaigou the amount of cloud is high in summer and autumn, and to meet the needs of small and medium-scale landscape pattern in this area. The high spatial resolution and multispectral images in 2004 and 2016 are selected respectively for the study.

\begin{tabular}{|c|c|c|c|}
\hline Receiving Time & Satellite & Resolution & Cloud \\
\hline 2016.03 .18 & Landsat8 & $15 / 30 / 100$ & 2.45 \\
2004.01 .29 & Landsat5 & $30 / 120$ & 13.67 \\
2016.09 .23 & Pleiades & $0.5 / 2$ & 0 \\
2004.11 .27 & Quick Bird & $0.6 / 2.4$ & 0 \\
\hline
\end{tabular}

Table 1. Data Sources 


\section{METHOD}

\subsection{Vulnerability Evaluation System}

According to the national standard Classification of Land Use Status (GB/T 21010-2017) (Resources, 2017), vertical ecological distribution of Jiuzhaigou, elements of Human landscape (Shao, et al., 2019) (Chen, et al., 2006) (Qian, et al., 2001), the actual situation of returning farmland to forest and grazing to grass (Shao, et al., 2016) (Zhang, 2009), The AHP was used to propose a vulnerability assessment system for material Human landscapes in the study area (Table 2).

\subsection{Index Analysis}

1. Intensity of the native activities: The intensity of the native activities was calculated according to the definition and algorithm for the intensity of human activities on the surface of $\mathrm{Xu}$ and the actual situation of the indigenous people in the study area (Xu, et al., 2015). The equation of it is as follows:

$$
\begin{aligned}
& \text { HAILS }_{\text {native }}=\left(S_{C L E-i} / S\right) \times 100 \% \\
& S_{C L E-i}=\left(\sum_{j=1}^{m} S L_{j} \times C I_{j}\right)
\end{aligned}
$$

\begin{tabular}{|c|c|c|c|c|}
\hline $\begin{array}{c}\text { I } \\
\text { Target }\end{array}$ & $\begin{array}{c}\text { II } \\
\text { Standard }\end{array}$ & $\begin{array}{l}\text { III } \\
\text { Index }\end{array}$ & Effect & Note \\
\hline \multirow{2}{*}{$\begin{array}{c}\text { Vulnerability Evaluation System } \\
\text { of Human Landscape }\end{array}$} & inside & $\begin{array}{l}\text { Intensity of Native } \\
\text { Activities } \\
\text { Human Landscape } \\
\text { Holding } \\
\text { Habitat Bio- } \\
\text { abundance }\end{array}$ & $\begin{array}{l}+ \\
+ \\
+\end{array}$ & $\begin{array}{l}\text { The relation between the area of Human } \\
\text { landscape and the total area of the Park } \\
\text { The relation between the area of Human } \\
\text { landscape and the number of natives } \\
\text { The environmental quality }\end{array}$ \\
\hline & outside & $\begin{array}{l}\text { Tour Heat } \\
\text { Tour traffic Heat } \\
\text { Intensity of Human } \\
\text { Tour Activities }\end{array}$ & $\begin{array}{l}- \\
-\end{array}$ & $\begin{array}{l}\text { The relation between the area of tour facilities and } \\
\text { the daily average tourist volume } \\
\text { The relation between the Park's road Mileage and } \\
\text { Daily Average Operating bus Mileage } \\
\text { The relation between the area of tour facilities and } \\
\text { the total area of the Park }\end{array}$ \\
\hline
\end{tabular}

Table 2. Evaluation system of Human landscape vulnerability

Where HAILS $S_{\text {native }}$ is the intensity of native activities, $S_{C L E-i}$ is the equivalent area of native construction in the ith year $(\mathrm{km} 2)$. $\mathrm{S}$ is the total area $(\mathrm{km} 2) . S L_{j}$ is the area of the jth land use type for native $(\mathrm{km} 2) . C I_{j}$ is the equivalent conversion coefficient of the native construction land for the jth land use type, $\mathrm{m}$ is the number of land use types.

2. Human Landscape Holding: the area of material Human landscape of the local people in the tourist spot was determined by the following formula:

$$
S_{c l h-i}=\left(\sum_{k=1}^{n} S_{k}\right) / P_{i}
$$

Where $S_{c l h-i}$ is the area of villages and temples in the ith year per native $(\mathrm{km} 2) . P_{i}$ is the number of natives in the ith year.

3.Habitat Bio-abundance: according to the Technical Specification for Eco-environmental Assessment (Protection, 2015), when the biodiversity index is not updated, the change of the biodiversity index is equal to the habitat quality index (Table 3). With the state policy action of Returning Farmland to Forests and Grazing to Grassland in Jiuzhaigou, the biological abundance formula is as follows:

$$
\begin{aligned}
& A_{c l}=0.35 \times B_{1}+0.21 \times B_{2}+0.28 \times B_{3}+ \\
& 0.04 \times B_{4}+0.04 \times B_{5}+0.04 \times B_{6}+0.01 \times B_{7}
\end{aligned}
$$

Where $A_{c l}$ is the habitat bio-abundance index of Human landscape and $B_{1}, B_{2}, B_{3}, B_{4}, B_{5}, B_{6}, B_{7}$ represent forest, grass, water, Human landscape, plank, road and unused respectively.

\begin{tabular}{|c|c|c|c|}
\hline & Forest & Grass & Water \\
\hline Weight & 0.35 & 0.21 & 0.28 \\
& Farm & Building & Unused \\
Weight & 0.11 & 0.04 & 0.01 \\
\hline
\end{tabular}

Table 3. Habitat Quality Index
4.Tour Heat: the ratio of the activity area of Plank with supporting service facilities to the daily average number of visitors in the year. The formula:

$$
H_{\text {tour }}=S /\left(\left(\sum_{j=1}^{n} P_{j}\right) / n\right)
$$

Where $H_{\text {tour }}$ is per capita area, the tourist facilities alone the plank (km2/people). $P_{j}$ is the number of visitors on the jth day (people). $\mathrm{n}$ is the number of days of the year. $\mathrm{S}$ is the sum of the area of the plank in the Park with supporting service facilities $(\mathrm{km} 2)$.

5. Tour Traffic Heat: The ratio of the total area of tour road with supporting service facilities to the daily average total activity area of the operating vehicles in the year, the formula is as follows:

$$
\begin{gathered}
C_{\text {Bus }}=S /\left(\left(\sum_{j=1}^{n} B_{j} / n\right) \times M_{0}\right) \\
B_{j}=\left(\left(\sum_{j=1}^{n} P_{j}\right) / n\right) \times\left(\sum_{i=1}^{m} O_{b u s-i}\right)
\end{gathered}
$$

Where $C_{B u s}$ is the ratio of the total area of the Park's tour road include bus- oriented tourism facilities along road, to the daily average total bus activity area in the year. $\mathrm{S}$ is the area of tour road with supporting service facilities $(\mathrm{km} 2) . B_{j}$ is the number of operating bus on the jth day. $n$ is the number of days of the year. M_0 is the measured average kilometers per bus in daily, $200 \mathrm{~km} / \mathrm{bus}$, and the average width of the road is $0.004 \mathrm{~km}, M_{0}$ is $0.8 \mathrm{~km} 2 /$ bus. $P_{j}$ is the number of visitors on the jth day of the year (people). $O_{b u s-i}$ is the ratio of measured operating bus output ratio in average daily to carrying capacity of 50 people of the bus, $0.8 / 50=0.016 .20$ people of the minibus, $0.2 / 20=0.01$, i is bus type, $\mathrm{m}$ is type number. 
6. Intensity of human tour activities: According to the definition and algorithm of human activity intensity on land surface by Xu $(\mathrm{Xu}$, et al., 2015), and with the situation of human tour activities in the Park the formula is as follows:

$$
\begin{array}{r}
\text { HAILS }_{\text {tour }}=S_{C E L-i} \times 100 \% \\
S_{C L E-i}=\left(\sum_{j=1}^{m} S L_{j} \times C I_{j}\right)
\end{array}
$$

Where HAILS $S_{\text {tour }}$ is the intensity of human tour activities, $S_{C E L-i}$ is the equivalent area of tour construction in the ith year (km2). $S_{C L E-i}$ is the area of the jth land use type for tour in the Park (km2). $C I_{j}$ is the equivalent conversion coefficient of the tour construction land for the jth land use type in the Park, $m$ is the number of land use types in the Park.

\subsection{Vulnerability Evaluation Model}

Vulnerability Evaluation Model/Index: It was developed according to the section 3.1, Non-dimensional Range
Normalization and Weight Method of Index Standard Deviation.

$F_{c l}=w_{1} \times H A I L S_{\text {native }}+w_{2} \times S_{c l h}+w_{3} \times A_{c l}+w_{4}$

$\times\left(100-H_{\text {tour }}\right)+w_{5} \times\left(100-C_{B u s}\right)+w_{6} \times\left(100-H A I L S_{\text {tour }}\right)$

(10)

Where $F_{c l}$ is the Vulnerability Evaluation Index of Human landscape, HAILS $S_{\text {native }}, S_{c l h}, A_{c l}, H_{\text {tour }}, C_{B u s}, H A I L S_{\text {tour }}$ respectively represent above 6 indexes, and $H_{\text {tour }}, C_{B u s}$, HAILS $S_{\text {tour }}$ are negative effects to Human landscape, which are transferred to $\left(100-H_{\text {tour }}\right),\left(100-C_{\text {Bus }}\right)\left(100-H A I L S_{\text {tour }}\right)$; $w_{1}, w_{2}, w_{3}, w_{4}, w_{5}, w_{6}$ is the weight of the 6 indexes respectively (Table 4 ).

\begin{tabular}{|c|c|c|c|c|c|c|}
\hline Indicators & HAILSnative & Sclh & Acl & Htour & Cbus & HAILStour \\
\hline StdDev(2004) & 1.673904 & 1.674224 & 46.225749 & 2.272640 & 1.385228 & 5.134271 \\
Weight(2004) & 0.028679 & 0.028685 & 0.791998 & 0.038938 & 0.023733 & 0.087967 \\
StdDev(2016) & 1.799885 & 1.797771 & 43.175452 & 2.734341 & 1.919619 & 5.134271 \\
Weight(2016) & 0.031822 & 0.031784 & 0.763339 & 0.048343 & 0.033939 & 0.090774 \\
\hline
\end{tabular}

Table 4. 2004 and 2016 The Standard deviation and weight

\section{RESULTS}

The vulnerability evaluation model of Jiuzhaigou Human landscape in 2004 and 2016, with reference to the ecological vulnerability evaluation (Zhang, Gao and Yang 2014), combined with Human landscape characteristics, the model is divided into five levels: the Very Zone (very vulnerability range), the High Zone (highly vulnerability range), the Balance Zone (medium vulnerability range), the Low Zone (low vulnerability range), the Non Zone (non-vulnerability range), according to which the results in 2004 and 2016 can be obtained (Figure. 1)

\section{DISCUSSION}

According to The Vulnerability Evaluation Model, the data of 2004 and 2016 are analyzed quantitatively from the change

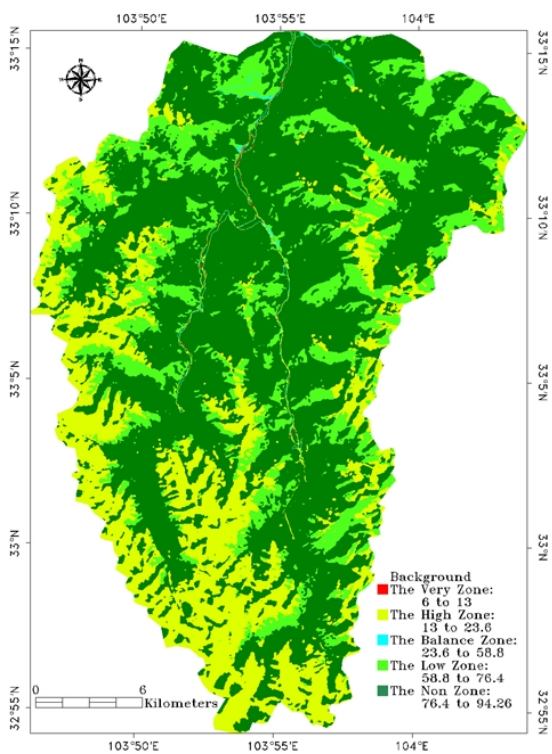

(a) 2004 detection of single index and the transfer of vulnerability evaluation levels.

\subsection{Indexes Analysis}

From the histogram analysis of the 2004 Human landscape vulnerability evaluation model (Figure. 2), there are three-pixel peaks, indicating that there are three large areas in the image of the Human landscape vulnerability evaluation model representing the evaluation value (Figure. 1). These three places have the greatest impact on vulnerability evaluation. The three locations are 17.7919 in the High Zone (161627 pixels), 62.5524 in the Low Zone (132429 pixels), and 94.263603 in the Non Zone (427528 pixels), which indicating the overall protection of Tibetan Human landscape that three large areas decisively impact evaluation values, one of which is negative and two of which are positive.

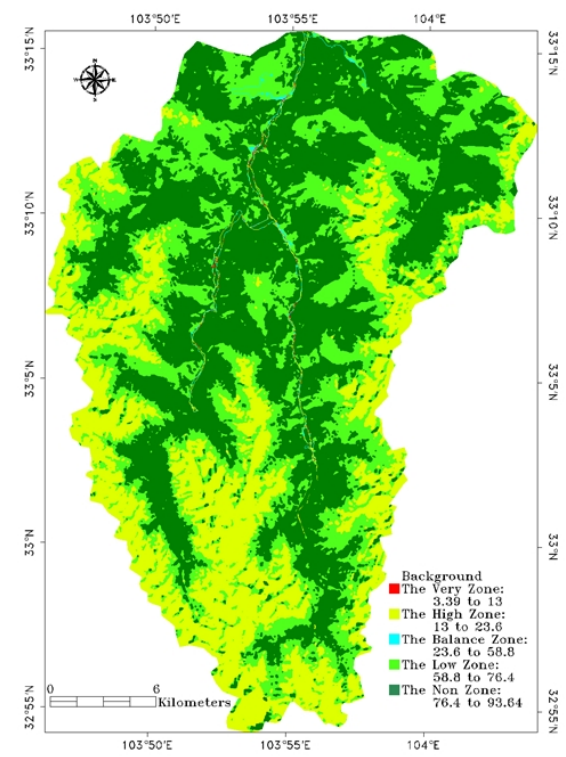

(b) 2016

Figure.1. The Vulnerability Evaluation Levels Image of Jiuzhaigou, Tibetan. Human Landscape 
In 2016, there were still three pixel peaks (Fig. 2), but the valued range of the High Zone increased to 19.3196 (183,793 pixels), indicating that the Very Zone is expanding to the High Zone. The extruded High Zone is also expanding, indicating that the impact of the High Zone has increased; the Low Zone has increased to 63.2037 (221,144 pixels), indicating that the Low Zone is significantly expanding into the Non Zone, and the Low Zone impacts on growth; the Non Zone fell to 93.6395 (316624 pixels), indicating that the overall valued range and area of the Non Zone were significantly reduced. Overall, the vulnerability of Jiuzhaigou Human landscape has increased significantly.

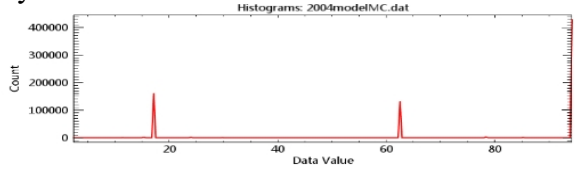

(a) 2004

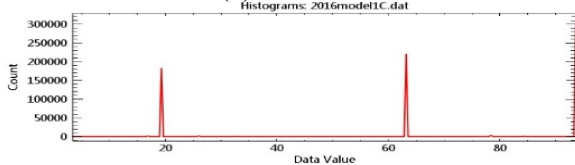

(b) 2016

\subsection{Transfer Analysis}

Figure. 2 Histogram of Model

Based on The Vulnerability Evaluation Levels of Jiuzhaigou Tibetan Human landscape in 2004 and 2016 (Fig.1), the results of the vulnerability transfer matrix in 2004-2016 is given in Table 5.The transfer results show that the overall change is obvious, especially the Non Zone, change is reduced from $388.46 \mathrm{~km} 2$ to $288.53 \mathrm{~km} 2$, accounting for $25.7247 \%$ of the Non Zone. It is the only zone that declines, and the rest of the zones have growth with different rates. It shows that natural change and rapid growth of human tour activities together extrude the space of the Non Zone, expansion to the Low Zone and pressure on the Balance Zone. It has high degree of negative impact on the High Zone and the Very Zone, which significant impact on Human landscape protection.

The Non Zone has the largest decline, from $105 \mathrm{~km} 2$ to 62.62 $\mathrm{km} 2$ from 2004 to 2016. There are three parts to the transfer. One is to transfer $23.12 \mathrm{~km} 2$ to the High Zone, and the other is to transfer $0.08 \mathrm{~km} 2$ to the Balance Zone. The Low Zone was transferred to $82.41 \mathrm{~km} 2$. In addition, the Non Zone was reduced from $58.69 \mathrm{~km} 2,71 \%$ to $43.91629 \%$ of the total area of the Park. According to field study, the Park did not suffer from large-scale damage incidents such as forest pests and diseases, forest fires in 2004 to 2016 and remote sensing images were taken in the snowpack period (Table 1). It demonstrates that the main reason for the transfer of $23.12 \mathrm{~km} 2$ to the High Zone due to the change of ice and snow cover. The transfer of $82.41 \mathrm{~km} 2$ to the Low Zone because of the disturbance identification of grass to shrub (Yang, et al., 2005).

\begin{tabular}{|c|c|c|c|c|c|c|}
\hline Area (Km2) & Very high & High & Balance & Low & Non & Class Total \\
\hline Very High & 0.23 & 0.31 & 0 & 0 & 0 & 0.54 \\
High & 0.12 & 121.6 & 0 & 22.09 & 23.12 & 166.92 \\
Balance & 0.03 & 0 & 1.9 & 0 & 0.08 & 2.02 \\
Low & 0.01 & 23.78 & 0 & 93.03 & 82.41 & 199.22 \\
Non & 0.01 & 1.45 & 0 & 4.23 & 282.84 & 288.53 \\
Class Total & 0.4 & 147.1 & 1.91 & 119.34 & 388.46 & \\
Class Changes & 0.17 & 25.54 & 0 & 26.31 & 105.62 & \\
Image Difference & 0.14 & 19.78 & 0.11 & 79.88 & -99.92 & \\
\hline
\end{tabular}

Table 5. The Transfer Matrix 2004-2016

The Low Zone has the largest growth rate, increasing from $119.34 \mathrm{~km} 2$ in 2004 to $199.22 \mathrm{~km} 2$ in 2016 . The largest contribution is the Non Zone, contributing $82.41 \mathrm{~km} 2$, followed by the High Zone contributing $23.78 \mathrm{~km} 2$. The transfer of $0.01 \mathrm{~km} 2$ in the Very Zone is small but significant. It shows that even natural changes and human tour activities have a great impact, as long as appropriate protecting measures can bring about positive impact.

The change of the Balance Zone was the smallest, from 1.91 $\mathrm{km} 2$ in 2004 to $2.02 \mathrm{~km} 2$ in 2016 . The increase of $0.11 \mathrm{~km} 2$ comes from $0.08 \mathrm{~km} 2$ in the Non Zones and $0.03 \mathrm{~km} 2$ in the Very Zones, which indicates that the Balance Zone has a strong buffer range (Fig. 2), which is a key area for the protection and development of Human landscape. The High Zone is the most dynamic in all levels. First, the High Zone transferred $0.31 \mathrm{~km} 2$ to the Very Zone from 2004 to 2016, while the Very Zone transferred to the High Zone by $0.12 \mathrm{~km} 2$. This indicates that the two zones transferred frequently, and their negative impact of tourism activities is far greater than protection. Second, the High Zone was transferred to the Low Zone of $23.78 \mathrm{~km} 2$, and at the same time it was transferred from the Non Zone and the Low Zone to $23.12 \mathrm{~km} 2$ and $22.09 \mathrm{~km} 2$ respectively.
Classification analysis of 2004-2016, shows that $23.7402 \mathrm{~km} 2$ was transferred from unused land to grass, while $23.0409 \mathrm{~km} 2$ and $22.0734 \mathrm{~km} 2$ were transferred from forest and grass respectively. The area of the Unused Land changes are highly similar to the High Zone. By referring to the Lansat8 image of the Park, the High Zone and the Unused Land are compared. Except for $1.6344 \mathrm{~km} 2$ area of the High Zone, which includes the human activity factors, of the tour road of Zechawa village, rest of the area of the High Zone is basically consistent with the bare rock, ice and snow cover of unused land. Based on above data of remote images, further comparative analysis of spectral characteristics of related regions has been presented in the two parts (Figure. 3).

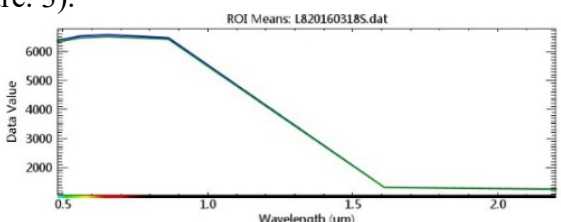

(a) Means of High Zone and Unused land 


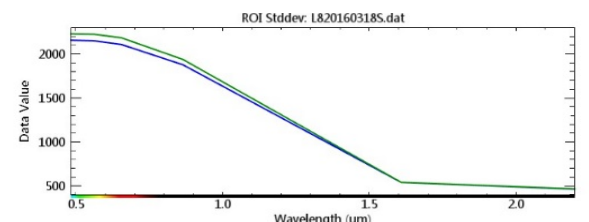

(b) StdDev of High Zone and Unused land Figure.3 Spectral Comparison

It can be concluded that the main reason for the change of the High Zone in the Park is that the composition of the Unused Land is bare rock, ice and snow cover. The remote sensing data of 2004 and 2016 reflects the active changes of ice and snow cover and also became one of the unavoidable natural environmental factors for the migration of the native people.

The Very Zone is the red line of protection. Although the area transfer only increases from $0.4 \mathrm{~km} 2$ to $0.54 \mathrm{~km} 2$, but it is the most drastic changed area. The analytical result (see Table 5) shows that, from 2004 to 2016, the Very Zone were transferred from the High zone to $0.31 \mathrm{~km} 2$, and respectively transferred to the High Zone of $0.12 \mathrm{~km} 2$, The Balance Zone of $0.03 \mathrm{~km} 2$, and the Low Zone of $0.01 \mathrm{~km} 2$. The Non Zone is $0.01 \mathrm{~km} 2$. On the one hand, it reflects that positive protective measures have achieved some results such as compulsory demolition of hotels in the Park, sleeping outside and touring inside, returning farm to forest, grazing to grass, zero garbage, zero sewage, zero discharge etc. But on the other hand, the rapid growth of human tourism activities not only offsets these positive impact measures, but also expands vulnerable area of $0.14 \mathrm{~km} 2$. It shows that the traditional management model cannot solve this problem, and it is necessary to reconstruct the protection and development system of Human landscape.

\section{CONCLUSIONS}

The vulnerability evaluation levels of Jiuzhaigou Tibetan Human landscape also highlights three aspects. The Very Zone might continue to transfer brutally and repeatedly. The regular evaluation of vulnerability is benefit to the development of precise protection measures. The Balance Zone has a strong buffer range that is necessary to deeply study its value in postearthquake reconstruction of Jiuzhaigou, which plays a decisive role in reconstructing a new model of Human landscape protection and development in Jiuzhaigou. The main reason for the mutual transfer of the High Zone and the Low Zone is bare rock, ice and snow cover, and that is an inevitable natural environmental factor for the migration of native along the human used roads in the valley.

\section{REFERENCES}

Anglestam, Per, BoresjöBronge, Laine and Mikusiński, Grzegorz. 2003. Assessing village authenticity with satellite images: a method to identify intact cultural landscapes in Europe [J]. Ambio. 12 1, 2003.

Chen, Yao, et al. 2006. The correlation between vegetation distribution and topographic factors in the northern part of Longmen Shanxi, Sichuan [J]. Journal of Ecology. 92006.

Chu, Chengfang. 2013. Study on the Change of Material Cultural Landscape in Zhouzhuang Ancient Town under the Background of Tourism Development [J]. Yunnan Geographic Environment Research. 2013.

Farina, Almo. 2000. The Cultural Landscape as a Model for the Integration of Ecology and Economics [J]. BioScience. 2000. Li, Deren, et al. 2014. From digital Earth to smart Earth [J]. Chinese Science Bulletin. 8 2014, pp. 722-733.
Liu, Shaoying, Zhang, Xiaoping and Zeng, Zongyong. 2007. Biodiversity of Jiuzhaigou Nature Reserve [M]. s.l. : Sichuan Publishing Group, 2007.

Maimaiti, Kremu. 2018. Spatial pattern analysis and landscape ecological sensitivity evaluation of historical and cultural sites in Turpan based on remote sensing and GIS [D]. s.l. : China University of Mining and Technology, 2018.

Martínez, Susana and Ramila, Pablo. 2010. Monitoring loss of biodiversity in cultural landscapes. New methodology based on satellite data $[\mathrm{J}]$. Landscape and Urban Planning. 2010.

Philip, Hamerton. 1885. Landscape [M]. s.l. : Boston: Roberts, 1885 .

Protection, Ministry of Environmental. 2015. National Standard "Technical Specification for Assessment of Ecological Environment Situation" (HJ192-2015) [M]. s.l. : Ministry of Environmental Protection, 2015.

Qian, H B, Xue, Y S and Tian, Y J. 2001. An overview of land resources rational use and assessment[J]. China Land Science. 4 15, 2001, pp. 14-19.

Resources, Ministry of Land and. 2017. National Standard "Classification of Land Use Status" (GB/T21010-2017) [M]. s.1.

: General Administration of Quality Supervision, Inspection and Quarantine $\backslash$ National Standardization Management Committee., 2017.

Sauer, Carl O.. 1925. The morphology of landscape [M]. s.l. : Univ. Calif. Publ. Geogr, 1925.

Shao, Zhenfeng, et al. 2019. Remote sensing monitoring of multi-scale watersheds impermeability for urban hydrological evaluation [J]. Remote Sensing of Environment. 2019.

Shao, Zhenfeng and Zhang, Linjing. 2016. Estimating Forest Aboveground Biomass by Combining Optical and SAR Data: A Case Study in Genhe, Inner Mongolia, China [J]. Sensors. 6 2016.

T.L, Saaty. 2001. Analytic hierarchy process. In: Encyclopedia of Operations Research and Management Science [J]. s.l. : Springer, 2001.

Xu, Yong, Sun, Xiaoyi and Tang, Qing. 2015. Intensity of human activities on land surface: concepts, methods and Applications [J]. Journal of Geography. 72015.

Yang, Chaojun, Hu, Tingxing and Liang, Yuxi. 2005. Selection of Optimum Time Phase for Remote Sensing Recognition of Forest Vegetation in Sichuan Province [J]. Journal of Sichuan Forestry Science and Technology. 52005.

Zhang, Xiaoping. 2009. Sustainable Development of World Heritage Tourism: A Case Study of Jiuzhaigou [M]. Southwest University of Finance and Economics Press, 2009. 